\title{
Improving Public Health through Nutrition Education
}

\section{Vera P Simovska-Jarevska*}

Department of Technology and Technical Sciences Veles, University St. Kliment Ohridski - Bitola, Macedonia

Keywords: Nutrition education; Research; Innovative technologies; Descriptors; Competencies; Doctoral degree

Education and nutrition are important fundamental conditions and resources for improving public health. Unhealthy nutrition is one of the key risk factors for developing main non-communicable diseases. Studies have confirmed that Macedonian population has unhealthy eating habits. Dietetics is not included in the curricula of Macedonian Medical Faculties. In order to improve population health, by improving the quality of nutrition education and research, after implementation of Master study for Nutrition and Food safety and quality [1], we determined the following objectives: -Supporting proactive partnership in defining national standards for the formulation of Doctoral study program for Innovation Technology for Food and Food Science and Nutrition; -Forming a set of competencies upon completion of studies; - Application of information and communication technology (ICT) and e-learning.

Analysing the results of numerous scientific findings that confirm the important role of food and nutrition in health promotion and prevention of nutrition-related diseases, we developed the Doctoral study programs with two modules. The first one module is focused on "The innovative technologies for food" and the second module is related to the "Food science and nutrition". The model of designing, planning and implementation of curriculum is in accordance with Dublin description 2005 [2], European standards for improvement of academic and practical curricula 2010 [3] and DIETS2 advanced competencies 2012 [4]. Proactive work with the industry and private companies is related to practice placement. Innovative application of ICT, e-learning and creating a website are intended for collaboration with EFAD, European Federation of Associations of Dieticians (EFAD) and other European and International Nutrition Networks.

These doctoral study programs will allow education of our own nutritionists who will be able to meet the domestic and global issues relating to food and nutrition, inclusion of the researchers and experts in the projects and in the healthcare teams, HEIs, food industry and they will be qualified to be responsible for production of healthy, quality, safe, environmentally friendly and affordable food for domestic and export needs. Also, these nutritional experts will contribute to changes in public health policy and health education strategy (2014-2020) in the area of "Public Health Enhancing through Nutrition Education".

\section{References}

1. Technological-Technical Faculty in Veles (2012) Master's degree in nutrition (in Macedonian). University St. Kliment Ohridski, Bitola, Technological-Technical Faculty in Veles.

2. Bologna Working Group on Qualifications Frameworks (2005) A framework for Qualification of the European Higher Education Area. Ministry of Science, Technology and Innovation, Copenhagen, Denmark.

3. Towards the European Higher Education Area - Bologna Process. The officia Bologna Process website (2007-2010).

4. European Commission/EACEA (2012) European Dietetic Advanced Competences (EDAC). Thematic Network for Dietetics - DIETS2, Brussels, Belgium. *Corresponding author: Vera P Simovska-Jarevska, Associate Professor,
The University St. Kliment Ohridski - Bitola,Coordinator of Postgraduate study
for Nutrition, Faculty of Technology and Technical Sciences, Public Health
Institutions - Skopje, Krste Misirkov bb, Skopje 1000, Republic of Macedonia, Tel:
+38923225402; E-mail: vera.simovska@uklo.edu.mk

Received March 10, 2015; Accepted March 11, 2015; Published March 14, 2015

Citation: Simovska-Jarevska VP (2015) Improving Public Health through Nutrition Education. J Nutr Disorders Ther 5: e120. doi:10.4172/2161- 0509.1000e120

Copyright: @ 2015 Simovska-Jarevska VP. This is an open-access article distributed under the terms of the Creative Commons Attribution License, which permits unrestricted use, distribution, and reproduction in any medium, provided the original author and source are credited. 